\title{
ANNEX G \\ International Standards and Classifications of Trade and Tourism
}

\section{International trade in services by mode of supply}

Trade statistics play an important information role in analysing the strengths and weaknesses of economies and in assessing the impacts of different policies and identifying opportunities offered by partners' markets. The World Trade Organisation, recognising the increasing role of the service sector, concluded the General Agreement of Trade in Services (GATS) in 1995, bringing services more into the spotlight of considerations about international trade. In addition to the general obligations that apply across all service sectors of all WTO Members, countries can choose which service sector and mode they wish to open up to trade. GATS has been an important driving force for the development of statistics on the international supply of services, ${ }^{1}$ and has influenced the establishment of a classification of four different modes of trade in services. The supply of health care services can take place in all four of these GATS modes, although not all are relevant to the measurement of trade under the System of Health Accounts.

To date, WTO Members have only made relatively limited commitments in health services (Mattoo et al., 2007). However, services are an important part of ongoing multilateral trade negotiations, and further liberalisation is expected in the future.

The following paragraphs describe the GATS four modes of supply, with particular reference to health services. GATS also sets out a classification that identifies relevant sectors and sub-sectors for the purposes of trade negotiating purposes, rather than for statistical purposes. The classification known as GNS/W/120 comprises 12 major categories, including "Health-related and social services".

\section{Mode 1: Cross-border supply}

Mode 1 "Cross-border supply" takes place when a service is supplied "from the territory of one Member into the territory of any other Member". This is comparable to trade in goods where the product is delivered across borders and the consumer and the supplier remain in their respective territories.

In the domain of health services, Mode 1 can take different forms: tele-health services $^{2}$ are the most prominent method, such as a physician providing a medical diagnosis to a patient via email, internet or telephone. A variety of services includes telediagnosis, tele-pathology, tele-radiology and tele-psychiatry and can cover preventive and curative care. The service can be delivered in real time (for example, through video 
conferences) or by store-and-forward, which means that the analysis is done at a different moment in time. For example, hospitals in the United States may send X-ray images electronically to India, where they are analysed by radiologists (Pollack, 2003). Another area relevant to SHA is the provision of health insurance by non-resident entities.

In addition to electronic delivery of health services, this also includes the shipment of laboratory samples, diagnosis and clinical consultations via traditional mail channels.

\section{Mode 2: Consumption abroad}

Mode 2 "Consumption abroad" takes place when the service is supplied "in the territory of one Member to the service consumer of any other Member", i.e. either the consumer or his property is abroad.

In theory, all health services could be purchased abroad; however, there exist practical constraints, such as the non-portability of health insurance or the capacity of the providing country. To date, the most prominent and most easily identifiable part of trade in health services is when patients travel abroad to receive medical treatment. This phenomenon is often called "medical or health tourism", hinting at a mix of health, well-being and leisure activities. In some instances this may be the objective, and the marketing of services may play upon opportunities to visit and experience a country at the same time as receiving quality care, but more often this concerns travel specifically and often exclusively for health care purposes and thus may more correctly be termed "health (or medical) travel" or "patient mobility". In other cases, tourists or persons on business travel may become sick or suffer an accident and need to seek medical care in the destination country.

The medical treatment of non-resident persons, i.e. person travelling abroad to the home country of the provider, can often be categorised into those seeking:

- Specialised or advanced treatment not available in the home country, generally sought by affluent patients from developing countries travelling to hospitals in industrialised countries or in neighbouring developing countries with superior health care standards;

- Or a price or quality advantage over the home country, generally sought by patients from industrialised countries who purchase affordable, high-quality treatment or alternative medicines and treatments in less developed countries.

\section{Mode 3: Commercial presence}

Mode 3 "Commercial presence" takes place through "the supply of a service by a service supplier of one Member, through commercial presence in the territory of any other Member". GATS recognises that it is often necessary for service suppliers to establish a commercial presence abroad to ensure closer contact with the consumer at various stages of production, distribution, marketing, sale and delivery as well as after-sales service. Commercial presence in a market abroad covers not only juridical persons in the strict legal sense, but also legal entities that share some of the same characteristics, such as representative offices and branches, e.g. medical services provided by a foreign-owned hospital.

The commercial presence of a foreign health care provider through, for example, capital investment, branches or affiliates, falls under mode 3. Commercial presence is mainly represented by the activities of foreign-controlled affiliates' trade. Health care companies in industrialised and some developing countries are increasingly engaging in joint ventures and alliances, resulting in several regional health care networks and chains. 
It should be noted that commercial presence is not defined as trade under the SHA (or balance of payments) framework. ${ }^{3}$ However, it may be of policy interest for some countries to monitor separately the extent of services delivered by foreign health care providers on the territory.

\section{Figure G.1.1. The four modes of supply for trade in health services as defined by GATS}

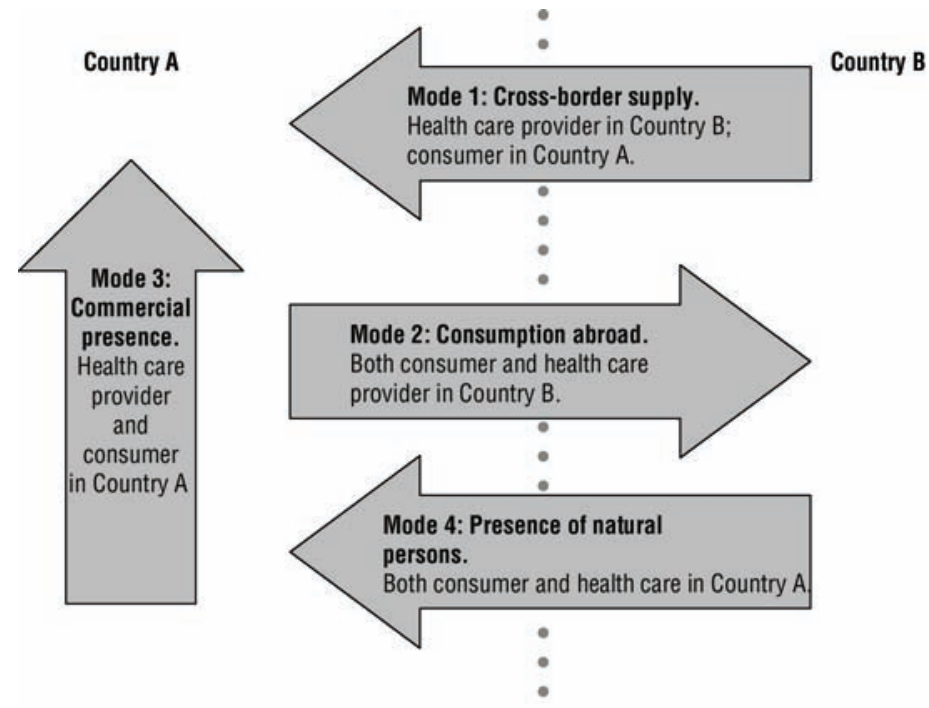

Source: IHAT for SHA 2011.

\section{Mode 4: Temporary presence of natural persons}

Mode 4 "Temporary presence of natural persons" takes place when an individual is temporarily present in the territory of an economy other than their own to provide a commercial service. GATS defines Mode 4 as the supply of a service by "a service supplier of one member, through the presence of natural persons of a Member in the territory of any other Member". Mode 4 is generally understood as covering:

- Contractual service suppliers, whether employees are of a foreign service supplier or self-employed;

- Intra-corporate transferees and foreign employees directly recruited by foreign established companies;

- Service sellers who enter the host country to establish contractual relationships for a service contract, or persons responsible for setting up a commercial presence.

It might sometimes be difficult to distinguish between those service providers that fulfil Mode 4 criteria and those that do not. However, it needs to be emphasised that from a public health perspective, it is very important to generate information on both the movement of health professionals under Mode 4 as well as outside Mode 4.

Examples in the health field include the movement of nurses, physicians, paramedics, midwives and other professionals from one country to another to provide health services. 
Short-term flows have been driven mainly by conscious strategies to promote the export of health services in order to earn foreign exchange and foster co-operation between governments.

\section{Balance of payments and national accounts}

The balance of payments is a statistical statement that provides a record of an economy's economic transactions with the rest of the world. In general terms, transactions in goods, services and incomes come under the current account, while a capital and financial account shows the financial resource flows. Services are arranged according to 12 broad standard services components. The 2008 System of National Accounts and the BPM6 have a common conceptual framework.

\section{Manual on Statistics of International Trade in Services (MSITS)}

The Manual on Statistics of International Trade in Services (UN, 2010) is built not only around the requirements of GATS but also on the key concepts of the System of National Accounts (SNA 2008) and the balance of payments (BPM6). The MSITS provides recommendations for the measurement of international trade in services and therefore provides a clear link to the measurement of trade in services under the System of Health Accounts. The MSITS sets out the Extended Balance of Payments Services Classification (EBOPS 2010), which provides a greater level of detail to the BPM6 classification of services and has correspondence tables with standard product and industry classifications. ${ }^{4}$ The coverage of the MSITS goes beyond that required by the System of Health Accounts, in that it allows for the separate identification of services delivered through locally established, but foreign controlled enterprises. Such transactions are covered by Foreign Affiliates Statistics (FATS). Although this information may be of importance to governments and policy makers, this distinction among health care providers is not made in the SHA supplementary trade tables.

Within the EBOPS 2010 classification (Table G.1.1), health services approximating to personal health care ${ }^{5}$ are split between two classes, depending on their mode of supply:

- 4.2.1. Health-related travel (corresponding to Mode 2 of GATS);

- 11.2.1. Health services (either Mode 1 or part of Mode 4).

Health-related travel

Of the two categories, the more important for most countries is "health-related travel"; the nature of most health care requires the presence and co-location of patient and healthcare provider, entailing the movement of one or the other. In this case, it is the movement of the patient abroad that is covered under the item "Travel" (EBOPS 4). Any services provided as a result of a non-resident provider moving (temporarily) across the border would be included under the "Health services" category.

The concept of "Travel" as part of services under the MSITS and BPM6 differs from most other traded services in that it does not refer to a specific product. Travel is defined as "goods and services, for own use or to give away, acquired from an economy, by nonresidents during visits to that economy". It covers stays of any length, provided there is "no change in residence" (normally taken as less than a year). However, in contrast to tourism statistics (see the next section), this also covers students and patients staying more than a year, as well as the consumption of seasonal, border and other short-term workers. Also 
important from the SHA perspective is the inclusion of third-party payments, e.g. health costs paid or reimbursed by government or insurers and in theory the imputation of social transfers in kind, e.g. government consumption expenditure on non-market health services.

Travel is broken down into Business travel and Personal travel. Business travel covers all the goods and services acquired by persons whose primary purpose of travel is business. This includes not only employees and self-employed persons travelling on business, but also cross-border, seasonal and short-term workers. Therefore, all expenditure items, including any health goods and services, would be included under Business travel. On the other hand, Personal travel covers the goods and services acquired by persons going abroad for any purpose other than business. MSITS 2010 recommends a further breakdown of personal travel into three subcomponents, one of which is Health-related. This, in effect, measures the consumption of all goods and services (i.e. food, transport, accommodation, etc.) - not just the health services acquired - by persons whose primary purpose for travelling is for health or medical reasons.

However, an alternative breakdown of Travel by product is also recommended, which provides a much closer link to the requirements of health accounts. There is a split into subcategories such as local transport and accommodation, as well as a category of other travel-related services, with health services as a suggestion. This kind of breakdown would gather together the consumption of health services by residents abroad, irrespective of the main purpose of travel. Note, however, that the purchase of any medical goods by travellers would not be included in this category.

\section{Health services}

Health services forms one part of the EBOPS first-level category "Other personal, cultural or recreational services" and equates to CPC Ver. 2 Group 931 (and class 9321 Residential health-care services other than by hospitals) covering human health services provided by hospitals, doctors, nurses and paramedical and similar personnel, as well as laboratory and similar services, whether rendered remotely (through telemedicine or telediagnosis) or on-site. Included are diagnostic-imaging services, pharmaceutical, radiology and rehabilitation services. This equates to the cross-border provision of health services (Mode 1), but also includes the presence of a non-resident health-care provider on the territory (Mode 4). It should be noted that in contrast to health services under travel, health services here can include both services provided provider-to-provider (i.e. diagnosis services from a laboratory in one country provided to a laboratory or hospital in another country) in addition to services provided directly to a patient. This important distinction is further discussed under the section intermediate and final use.

Any health services supplied by and to governments should also be included under health services. In practice it may be that some services will not be able to be separately identified and are included under "Government goods and services not included elsewhere (n.i.e)". This can be relevant to health services provided to embassy or military staff posted abroad.

MSITS 2010 also provides suggestions for the complementary grouping of EBOPS 2010 categories, including C.8. Total health services. This aggregates the two components:

- Health services (product breakdown of travel, other services); and

- Health services (under other personal, cultural and recreational services). 
Reporting of this complementary grouping is a close proxy to what is required under trade in health services under the SHA framework. Some additional items and adjustments related to SHA boundaries would in principle still be required.

Table G.1.1. Health services under the EBOPS 2010 classification

\begin{tabular}{|c|c|c|}
\hline Code & Description & \\
\hline \multirow[t]{6}{*}{4 Travel } & 4.1 Business & \\
\hline & $\begin{array}{l}\text { Acquisition of goods and services by border and seasonal } \\
\text { workers }\end{array}$ & \\
\hline & Other & \\
\hline & 4.2 Personal & 4.2.1 Health-related \\
\hline & & 4.2.2 Education-related \\
\hline & & 4.2.3 Other \\
\hline \multirow[t]{4}{*}{11 Personal, cultural and recreational services } & 11.1 Audiovisual and related services & \\
\hline & 11.2 Other personal, cultural and recreational services & 11.2.1 Health services \\
\hline & & $\begin{array}{l}\text { 11.2.2 Education } \\
\text { services }\end{array}$ \\
\hline & & 11.2.3 Other \\
\hline \multicolumn{3}{|l|}{ Alternative EBOPS groupings } \\
\hline \multicolumn{3}{|l|}{$\begin{array}{l}8 \text { Health services = health services in travel + } \\
\text { health services in personal, cultural and } \\
\text { recreational services }\end{array}$} \\
\hline
\end{tabular}

Source: UN (2010).

Other relevant EBOPS categories

To achieve a full mapping to health care according to the boundaries of SHA, reference should also be made to other EBOPS categories, such as business services, other personal services and insurance services. It is clear that the EBOPS classification (and data sources) is not sufficiently detailed to provide much information that is relevant to health spending.

In the case of insurance, accident and health insurance provided to and by nonresidents cannot be separately identified from a broader sub category of Other direct insurance. In theory, the service charges for resident policyholders with non-resident insurers (and vice versa) should be taken into account in estimating health spending (as a component of HC.7 Governance, and health system \& financing administration).

Similarly, despite the increased use of overseas outsourcing in such areas as health system governance, planning and administration (or research and development), this does not warrant any explicit categorisation in Business services.

Finally, the boundaries of health expenditure under SHA mean that some areas of personal care related to parts of care services to the elderly and disabled lie outside the boundaries of Health care services under the EBOPS and are included instead under Other personal, cultural and recreational services n.i.e.

\section{Tourism statistics and the Tourism Satellite Account (TSA) ${ }^{6}$}

Definitions of trade in health goods and services under the SHA framework and the concepts adopted for tourism satellite accounting show many similarities that may be useful in identifying relevant data sources. First and foremost, tourism is primarily a demand-side phenomenon that refers to the activities of visitors and their role in the acquisition of goods and services across many different industries, including health goods 
and services. Tourism, as defined under tourism statistics, goes beyond what may be traditionally perceived to include persons travelling (under certain conditions explained below) for holiday, leisure and recreation purposes and also includes, among others, business, education, and importantly, health. However, if the purpose of a trip is for employment or to earn an income, then the trip is not considered as a tourist trip, and the individual cannot be considered as a visitor. Therefore, in the case of seasonal and border workers, any expenditure on health would be excluded from the Tourist Satellite Account.

The concepts of economic territory and residence are defined in the same way as in the balance of payments. Tourism statistics make the further distinction between "the country of residence" and citizenship or nationality. Nationality or citizenship is related to the country issuing the passport or identity card; a person may be resident in one country but hold the nationality of another - or indeed hold dual nationality in some cases. This may be an important distinction regarding health services abroad, since much of the crossborder traffic involves nationals returning for treatment to their country of origin, where they still hold nationality. In addition, statistics of travellers collected at borders may often identify only the nationality (as stated in the passport) rather than the country of residence. For the purpose of tourism statistics and indeed for health accounts, persons are classified according to their country of residence.

IRTS 2008 makes a clear distinction between "travel" and "travellers" in the BoP sense, and "tourism" and "visitors" - the latter terms being subsets of the former: such a distinction builds on the concept of "usual environment" (one of the key concepts in tourism statistics). The purpose of introducing such a concept is to exclude from visitors those travellers who commute regularly between their place of usual residence and their place of work or study, or who frequently visit places as part of their regular life routine, for instance, for health care.

In relation to the country of reference, the following three basic forms of tourism can be distinguished:

- Domestic tourism, ${ }^{7}$ which comprises the activities of a resident visitor within the country of reference either as part of a domestic tourism trip or part of an outbound tourism trip;

- Inbound tourism, which comprises the activities of a non-resident visitor within the country of reference on an inbound tourism trip;

- Outbound tourism, which comprises the activities of a resident visitor outside the country of reference, either as part of an outbound tourism trip or as part of a domestic tourism trip.

Although visitors are then divided into residents and non-residents for the purposes of domestic and inbound tourism, non-resident visitors are a category distinct from nonresidents abroad. For example, border workers living in Belgium and regularly crossing into France would be excluded from visitors, and any expenditure on health goods and services made in France would not be included in the French inbound tourist consumption figures. Some other differences exist between the scope of visitors in tourism statistics and that of non-residents used in SHA, e.g. refugees, long-term students and patients (that is, those staying longer than one year) are also excluded from visitors.

The main priority of the TSA is to provide information on internal tourism, i.e. to measure the consumption of inbound and domestic visitors in the economy. The consumption of residents abroad is of a lesser priority to TSA compilers, since there is no 
direct impact in the economy of reference. Therefore, from the SHA point of view, information coming from the TSA on inbound tourism may be most useful in identifying the consumption of health services by non-residents, i.e. exports. Visitor flows - in nonmonetary terms - can be split between visitors and other travellers with no tourist purpose. The standard classification of a tourism trip according to main purpose includes a category: "health and medical care".

In addition to the traditional measurement of the characteristics and activities of visitors by means of non-monetary data, IRTS 2008 also refers to the measurement of tourism expenditure defined as "the amount paid for the acquisition of consumption goods and services, as well as valuables, for own use or to give away, for and during tourism trips. It includes expenditure by visitors themselves as well as expenses that are paid for or reimbursed by others." The wider measure of tourism consumption is a TSA concept that is more inclusive because it also includes "services associated with vacation accommodation on own account, tourism social transfers in kind and other imputed consumption". For the purposes of health, this distinction can be useful, since it includes, in theory, government consumption expenditure on individual non-market services or products including social services and health that can be considered as benefiting visitors (social transfers in kind).

The Tourism Satellite Account is organised according to products (using the internationally approved classifications of products CPC Ver. 2) - that is, the goods and services consumed by visitors. However, since the product breakdown of tourist expenditure is based primarily on information provided by visitors, the classification for collection of this expenditure is usually based on purpose, in this case the COICOP. Consequently, there is a need to adapt data based on the COICOP - a functional classification - to the CPC - a product classification - which can be linked to products (CPC) and activities (ISIC). Tourism products are classified according first to broad categories: consumption products/non-consumption products. The former category is further divided into tourism characteristic products (characterised by the fact that the tourism expenditure on the product accounts either for a significant share of total tourism expenditure and/or represents a significant share of the supply of the product in the economy) and other consumption products. Tourism characteristic products are then subdivided into internationally comparable tourism characteristic products, which are a standard list of products defined in terms of CPC Ver. 2, such as accommodation services, food and beverages and transport. The other subcategory refers to country-specific tourism characteristic products, and this is where individual countries can include products that may have particular relevance to their countries, but are limited worldwide. This may be the case for countries where the promotion of health or medical tourism is seen as an important area, and as such the inclusion of specific questions related to health in tourist surveys or the development of specific surveys of health providers can be seen as an important source of information. ${ }^{8}$

It should be noted that a specific category "health and medical care" corresponds closely to the main purpose of the trip, and as such the incidental purchase of health care products and occasional health services may be allocated into non-tourism-related consumption products in the first instance.

Additional tables of the TSA show both how this tourist demand is met by domestic supply and imports as well as the link with non-monetary information. 


\section{Notes}

1. Although the supply of health services by governmental organisations such as national health services is included in the SHA and SNA views of trade in health services, it should be noted that GATS does not cover these.

2. There are currently a number of alternative terms in use: tele-medicine, e-medicine and e-health

3. Foreign ownership is not a criterion applied in determining the resident status of health care providers under SHA. Thus, foreign-owned resident health care providers are classified under the appropriate domestic provider category, and the health care goods and services consumed are treated accordingly.

4. The MSITS provides correspondence tables between the EBOPS classification, CPC Ver. 2 and GNS/ W/120 (a Services Sectoral Classification drawn up by the GATT Secretariat for trade negotiating purposes rather than statistical classification).

5. Note that medical goods consumed abroad are considered as part of services and reported under the category "Travel" in the MSITS.

6. In order to provide internationally comparable data on the different aspects of tourism, the World Tourism Organisation (UNWTO) has developed a set of basic concepts, definitions and classifications. The International Recommendations for Tourism Statistics 2008 (IRTS 2008) includes an alignment with other economic statistics. The development of a Tourism Satellite Account analyses in detail all the aspects of demand for goods and services associated with tourism. The Tourism Satellite Account: Recommended Methodological Framework 2008 (TSA: RMF 2008) provides the link between tourism statistics and the standard tables of the SNA 2008.

7. It is important to note differences in the use of the word "domestic". In tourism statistics, "domestic" refers to activities of residents within the country of residence, whereas in national accounts and SHA, "domestic" refers to activities of residents irrespective of where this takes place. In tourism statistics, the latter corresponds to "national tourism".

8. For example, Switzerland specifically includes "Health care" as a tourism-connected product in their Tourism Satellite Account (Swiss Federal Statistical Office, 2008). 


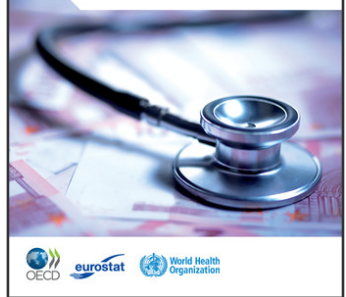

\section{From:}

A System of Health Accounts

2011 Edition

Access the complete publication at:

https://doi.org/10.1787/9789264116016-en

\section{Please cite this chapter as:}

OECD/World Health Organization/Eurostat (2011), "Annex G: International Standards and Classifications of Trade and Tourism", in A System of Health Accounts: 2011 Edition, OECD Publishing, Paris.

DOI: https://doi.org/10.1787/9789264116016-25-en

This work is published under the responsibility of the Secretary-General of the OECD. The opinions expressed and arguments employed herein do not necessarily reflect the official views of OECD member countries.

This document and any map included herein are without prejudice to the status of or sovereignty over any territory, to the delimitation of international frontiers and boundaries and to the name of any territory, city or area.

You can copy, download or print OECD content for your own use, and you can include excerpts from OECD publications, databases and multimedia products in your own documents, presentations, blogs, websites and teaching materials, provided that suitable acknowledgment of OECD as source and copyright owner is given. All requests for public or commercial use and translation rights should be submitted to rights@oecd.org. Requests for permission to photocopy portions of this material for public or commercial use shall be addressed directly to the Copyright Clearance Center (CCC) at info@copyright.com or the Centre français d'exploitation du droit de copie (CFC) at contact@cfcopies.com. 